\title{
Predator-Based Selection And The Impact of Edge Sympatry On Components of Coral Snake Mimicry
}

Lauren Wilson ( $\square$ lw16271@georgiasouthern.edu )

Georgia Southern University https://orcid.org/0000-0002-2259-7560

George Lonsdale

University of Plymouth

John David Curlis

University of Michigan

Elizabeth Hunter

Georgia Southern University

Christian L. Cox

Florida International University

\section{Research Article}

Keywords: Natural selection, Batesian mimicry, sympatry, allopatry, aposematism, predation, antipredator traits

Posted Date: May 13th, 2021

DOI: https://doi.org/10.21203/rs.3.rs-493560/v1

License: (c) (i) This work is licensed under a Creative Commons Attribution 4.0 International License. Read Full License

Version of Record: A version of this preprint was published at Evolutionary Ecology on January 11th, 2022. See the published version at https://doi.org/10.1007/s10682-021-10143-8. 
1 Predator-based selection and the impact of edge sympatry on components of coral snake mimicry

3 Lauren Wilson ${ }^{1}$, George Lonsdale ${ }^{2}$, John David Curlis ${ }^{1,3}$, Elizabeth A. Hunter ${ }^{1}$, and Christian L.

$5 \quad{ }^{1}$ Georgia Southern University, Statesboro, Georgia, USA

$6 \quad{ }^{2}$ University of Plymouth, Plymouth, UK

7 ' ${ }^{3}$ University of Michigan, Ann Arbor, Michigan, USA

$8 \quad{ }^{4}$ Florida International University, Miami, Florida, USA

10 Author for correspondence: Lauren Wilson, laurenwilson25@gmail.com, ORCID:

11 https://orcid.org/0000-0002-2259-7560

12

13 George Lonsdale: georgelonsdale1@gmail.com

14 John David Curlis: curlisjd@umich.edu

15 Elizabeth Hunter: elizabethhunter@georgiasouthern.edu; ehunter1@ vt.edu

16 Christian L Cox: ccox@ fiu.edu

17 Keywords: Natural selection, Batesian mimicry, sympatry, allopatry, aposematism, predation,

18 antipredator traits

19 Word Count: 3858

202 tables, 4 figures

21 Supplemental material: 4 tables, 1 figure, extended methods

22 Acknowledgements

23 We thank Mairéad Corr, Maddy Blunt, Georgina Davey, Hunter McCall, Rodrigo Morales, 24 Harry Pym-Davis, and Chris Phipps for field assistance. Declan Crace and Tom Martin were 25 instrumental in the design and implementation of this research. We thank the Department of 26 Biology and Graduate Student Organization at Georgia Southern University and Operation 27 Wallacea for supporting this project. Our sincere gratitude is extended to Lance McBrayer, 28 Adam Rosso, Albert Chung, and Scott Meyer for advice during this project. 


\section{Abstract}

Mimicry is a vivid example of how predator-driven selection can impact phenotypic

32 diversity, which itself can be influenced by the presence (sympatry) or absence (allopatry) of a

33 dangerous model. However, the impact of sympatry and allopatry on predation on mimicry

34 systems at fine spatial scales (e.g., edge sympatry, allopatry) is not well understood. We used a

35 clay replica study in a montane tropical site in Honduras to test the impact of edge sympatry on

36 1) overall attack rates, 2) the fitness benefit of mimetic coloration, 3) predation on specific

37 mimetic signal components, and 4) temporal variation in predator-based selection on mimicry

38 components. Unlike previous research, we found that mimetic phenotypes received significantly

39 more attacks than cryptic replicas in edge sympatry, suggesting that mimetic phenotypes might

40 not confer a fitness benefit in areas of edge sympatry. Additionally, we documented temporal

41 variation in predator-based selection, as the impacts of allopatry on predatory attacks varied

42 among years. Our results imply that the effect of sympatry and allopatry on predator-based

43 selection in mimicry systems may be more complex than previously thought for species-rich

44 assemblies of coral snakes and their mimics in the montane tropics. 


\section{Introduction}

Although phenotypic diversity is extremely well-studied in evolutionary biology, the means by which phenotypic patterns occur and are maintained remain unclear in many systems. In order for evolution by natural selection to occur in a population, the population must have variation in a heritable phenotype and a selective force (such as predation) acting upon the population (Endler, 1986; Freeman \& Herron, 2004). Studying predation pressure is an effective method to understand phenotypic diversity because the selective agent is known, and much has been learned by analyzing the evolutionary drivers of antipredator traits such as warning coloration (e.g. aposematism) and mimicry (Brodie III, 1993; Brodie III \& Janzen, 1995; Ham et al., 2006; Kleisner \& Saribay, 2018; Kuchta, 2005; Pfennig et al., 2001; Pfennig et al., 2007; Quicke, 2017). In organisms with aposematism, conspicuous coloration acts as a signal to potential predators that these organisms are inedible or dangerous, thus promoting predator avoidance (Arbuckle \& Speed, 2015; Kuchta, 2005; Leimar et al., 1986; Mappes et al., 2005; Ruxton et al., 2004). In turn, mimics honestly (Müllerian) or deceitfully (Batesian) replicate this signal and thereby gain protection (Quicke, 2017). Aposematism and mimicry therefore provide a direct link between phenotypic traits and predator-driven selection and can offer strong evidence for how evolution by natural selection operates in nature (Davis Rabosky et al., 2016; Endler, 1986; Harper \& Pfennig, 2007; Kleisner \& Saribay, 2018; Kuchta, 2005; Leimar et al., 1986; Stevens \& Ruxton, 2012). Mimetic phenotypes are known to be subjected to various types of selection, including directional, stabilizing, and frequency-dependent selection (Akcali et al., 2018; Akcali \& Pfennig, 2014; Cox \& Davis Rabosky, 2013; Holmes et al., 2017; Lindstedt et al., 2011; Mappes \& Alatalo, 1997; Ruxton et al., 2004), and these selective forces can themselves be influenced by the spatial co-occurrence (sympatry) or lack thereof (allopatry) of 
models and mimics (Finkbeiner et al., 2018; Greene \& McDiarmid, 1981; Harper \& Pfennig,

69 2007; Kikuchi \& Pfennig, 2013; Pfennig, 2016; Pfennig et al., 2001; Pfennig et al., 2007;

70 Pfennig \& Mullen, 2010; Ruxton et al., 2004). Nevertheless, the evolutionary effects of sympatry

71 and allopatry are complex and only well studied in some systems (Akcali \& Pfennig, 2017; Cox

72 \& Davis Rabosky, 2013; Harper \& Pfennig, 2007; Holmes et al., 2017; Pfennig et al., 2001;

73 Pfennig et al., 2007; Pfennig \& Mullen, 2010).

The effectiveness and precision of mimicry vary with presence and abundance of models

75 (Akcali \& Pfennig, 2017; Finkbeiner et al., 2018; Harper \& Pfennig, 2007; Kikuchi \& Pfennig,

76 2013; Lindström et al., 1997; Owen \& Owen, 1984; Pfennig et al., 2001; Ruxton et al., 2004;

77 Yamauchi, 1993). For example, mimetic precision decreases in areas with denser populations of

78 models and increases where the model is rare (Akcali \& Pfennig, 2014; Harper \& Pfennig,

79 2007). Because population densities often decrease in geographic range margins (Hengeveld \&

80 Haeck, 1982), the relative distance from the sympatry-allopatry border (i.e. edge sympatry vs

81 deep sympatry) can affect mimetic precision. This link between selection and sympatry could be

82 even more important when the model is deadly (Lindström et al., 1997; Pough, 1988; Quicke,

83 2017). In coral snake mimicry complexes, for example, some studies suggest elements of color

84 pattern mimicry are precise in edge sympatry, may be relaxed in deep sympatry, and may not

85 convey a fitness advantage at all in allopatry, at least in temperate mimicry systems (Harper \&

86 Pfennig, 2007; Pfennig et al., 2007). Other studies have found that where coral snakes were

87 recently extirpated, their mimics have become more precise, further suggesting that mimicry

88 should be more precise in areas where the model is rare and suggesting that directional selection

89 may favor precise mimicry in a newly allopatric region (Akcali \& Pfennig, 2014). 
Nevertheless, research regarding the evolutionary consequences of sympatry/allopatry on

91

92

coral snake mimicry has largely been focused on temperate zones, with few studies conducted in diverse tropical ecosystems and even fewer focused on montane tropical environments. In contrast to temperate regions, the enormous taxonomic and phenotypic diversity of tropical systems results in a much wider range of aposematic color patterns of both coral snakes and mimics (Savage \& Slowinski, 1992). Moreover, this diversity in color patterns of models and mimics persists despite the fact that aposematism generally leads to stabilizing selection on model phenotypes, suggesting that selection may act differently in areas with high biodiversity (Joron \& Mallet, 1998; Mallet \& Turner, 1997). The montane tropics not only have higher biodiversity for both coral snakes and mimics than temperate systems, but they also provide areas of allopatry and edge sympatry in close geographic proximity and under a variety of different predator assemblages (Townsend \& Wilson, 2008). Thus, the poorly-studied montane tropics represent an excellent study system for understanding how mimicry is influenced by geography at both local (sympatry vs. allopatry) and regional (tropical vs. temperate) scales.

We studied the impact of edge sympatry and allopatry on predation rates on coral snake banding patterns in the montane tropics of Honduras. Highly venomous, elapid coral snakes have evolved aposematism via a brightly colored and banded phenotype, which has subsequently been mimicked by a variety of nonvenomous colubroid snakes in a classic example of Batesian mimicry (Davis Rabosky et al., 2016; Greene \& McDiarmid, 1981; Hinman et al., 1997; Pfennig et al., 2007; Pough, 1988; Quicke, 2017). This mimicry system provides an excellent model to study the evolutionary drivers of phenotypic diversity because it involves multiple species of both models and mimics and spans multiple habitats (Quicke, 2017; Savage \& Slowinski, 1992). However, most research on coral snake mimicry has focused on species-poor temperate systems 
113 that often have only one model and one to three mimics. Furthermore, studies focusing on the

114 effects of the depth of sympatry, and indirectly model abundance, have also been centered on

115 temperate systems that lack the species diversity of the tropics (Akcali \& Pfennig, 2014; Akcali

116 \& Pfennig, 2017; Harper \& Pfennig, 2007; Pfennig et al., 2007). The few studies performed in

117 the tropics have rarely taken place in montane habitats where elevational gradients exclude coral

118 snakes in some areas, which creates a mosaic of sympatric and allopatric regions in close

119 geographic proximity (McCranie \& Savage, 2011). Thus, we know relatively little about the

120 evolution of signal components of coral snake mimicry in the diverse tropics where multiple

121 model and multiple mimic species occur in sympatry and in close allopatry (Davis Rabosky et

122 al., 2016; Harper \& Pfennig, 2007; Pfennig et al., 2001; Pfennig et al., 2007). By analyzing

123 predation rates on mimicry patterns in edge sympatry and allopatry in the montane tropics, we

124 can achieve a greater understanding of which mimetic phenotypes are most successful in areas

125 with a relatively high diversity of phenotypes.

We conducted a field experiment using mimetic and non-mimetic clay replicas of snakes

127 placed along an elevational gradient in Honduras to study the interaction of coral snake

128 sympatry/allopatry and replica color pattern on predation rate. First, we tested whether overall

129 attack rates on replicas varied between edge sympatry and allopatry, with higher attack rates

130 suggesting a greater intensity of predator-mediated selection. Second, we tested which color

131 patterns were attacked most in edge sympatry or allopatry. Empirical research suggests that

132 mimetic phenotypes should convey a fitness advantage in edge sympatry but should suffer a

133 fitness cost in allopatry (Akcali \& Pfennig, 2017; Harper \& Pfennig, 2007; Ries \& Mullen,

134 2008). However, if mimetic phenotypes are attacked less than non-mimetic phenotypes in both

135 habitats, this implies that the fitness advantage of mimetic signals is maintained in allopatry 
136 close to the range edge. Conversely, mimetic phenotypes being attacked more than non-mimetic

137 phenotypes in both edge sympatry and allopatry would imply that mimicry is maladaptive in

138 both habitats. Third, we compared attack rates among mimetic replicas to determine which

139 mimetic signal components may be most important in deterring predation. Finally, we examined

140 whether attack rates varied over time, which could suggest frequency-dependent selection, in

141 which the most common phenotypes are attacked disproportionally more by predators, in turn

142 creating spatial and temporal variation in which color patterns are favored (Holmes et al., 2017).

143

144 Materials \& Methods

145 Study site

We conducted our study in Cusuco National Park, Honduras, from June to August of

1472018 and 2019. This tropical montane environment is characterized by broad-leaf, pine, and

148 mixed forests and is situated at $\sim 115 \mathrm{~m}$ to $\sim 2200 \mathrm{~m}$ in elevation. Importantly, Cusuco National

149 Park encompasses populations of coral snakes and coral snake mimics in both sympatry and

150 allopatry (Alliance, 2019; Brown \& Arrivillaga, 2017; Townsend \& Wilson, 2008). Over the

151 period of a decade, herpetofaunal diversity was monitored using opportunistic sampling.

152 Sampling occurred sporadically from May to August. Survey paths through the park were

153 walked by teams of 2-15 people, and each path was walked at least 6 times each year. When a

154 snake was encountered, it was identified and the GPS coordinates noted. Through this extensive

155 herpetofaunal research and monitoring in the park, surveyors have documented two species of

156 coral snakes (Micrurus diastema and Micrurus nigrocinctus) and nine species of coral snake

157 mimics (Geophis nephodrymus, Lampropeltis abnorma, Ninia sebae, Oxyrhopus petolarius,

158 Pliocercus elapoides, Scaphiodontophis annulatus, Scolecophis atrocinctus, Sibon dimidiatus, 
and Tropidodipsas sartorii) (Brown \& Arrivillaga, 2017; Townsend \& Wilson, 2008). GPS points of each of these species encountered in the surveys were plotted on a map of the park using ArcGIS (ArcGIS version 10.7.1, map projection WGS_1984_UTM_Zone_16N) (Fig. 1). We divided the park into $200 \mathrm{~m}$ elevational bands and plotted the number of coral snake and mimic species encountered in each band.

Field experiment

In order to assess predation rates on various mimetic and non-mimetic color patterns, we analyzed the number of attacks on clay replicas. We constructed these non-toxic, pre-colored clay replicas to have patterns loosely based on snakes found in the park. Replicas were either cryptic (brown) or mimetic (white-and-black banded, red-and-black banded, or tri-colored with red, white, and bands) (see electronic supplementary material, Fig. S1a). Clay replicas were arranged in tetrads containing each replica pattern along transects at different elevations in both sympatric and allopatric habitats (see electronic supplementary material, Table S1 and Fig. S1b). Tetrads were arranged on alternate sides of the transect to minimize proximity to other tetrads. Replicas were left out for a period of two weeks and checked every three to four days for marks of predation (e.g., beak, teeth, or claw marks). If a replica was attacked more than once during the two weeks, only one attack was counted. Each instance of attack was categorized by predator type (bird, mammal, or unidentifiable) and recorded.

\section{Statistical Analyses}

We analyzed the data using 1) contingency analyses of pooled transect data and 2) mixed effect models compared with information theoretic model selection. Contingency analyses were used to estimate differences in predation rates between clay replica types, habitats, and years, 
181 while mixed effects models and model selection were used to test whether coral snake sympatry

182 and color pattern had meaningful effects on attack rates (while accounting for spatial

183 autocorrelation of clay replicas within transects). To avoid missing patterns by discarding

184 ambiguous attack marks, we combined bird and mammal attacks into an overall "attacked"

185 category. We combined data from all transects and performed contingency analyses in JMP v

18613.1 .0 (SAS Statistical Institute, Cary, NC, USA). We created mixed effect logistic regression

187 models in R (version 3.5.2) and compared them using small sample size-corrected Akaike

188 information criterion (AICc) values to determine which statistical models were most effective in

189 predicting attack rates (Bates et al., 2015; Mazerolle, 2019; R Core Team, 2020). The response

190 variable for these statistical models was whether a replica was attacked or not attacked at any

191 point during the two-week period. The null models for each year included one term: a random

192 effect for the clay replica's transect. This random effect should account for most spatial

193 autocorrelation because tetrads within a transect were closer to each other than to tetrads in any

194 other transect. The remaining statistical models included transect as a random effect as well as all

195 potential linear combinations of level of sympatry (edge sympatry or allopatry), one of five color

196 variables, and an interaction between level of sympatry and replica color. The five color

197 variables were individual pattern (the pattern of the replica), the presence of red (two of the

198 replica patterns), the presence of white (two replica patterns), the presence of bands (three replica 199 patterns), or whether it was tricolor (one replica pattern).

\section{Results}

Coral snakes and mimics have been encountered in most of the same elevational bands 
203 but are notably absent above this threshold (Fig. 1b). Mimic species diversity peaks at 1400m,

204 but mimics are indeed encountered above $2200 \mathrm{~m}$ (Fig. 1c).

We found that both coral snake sympatry (Fig. 2) and elements of replica color pattern

206 (Fig. 3 and Fig. 4) had significant associations with predation rates. Total attack rates on clay

207 replicas were higher in allopatry than in edge sympatry in 2019 (contingency analysis, $\chi^{2}=$

$20821.702, p<0.0001$ ) but not in 2018 (contingency analysis, $\chi^{2}=1.134, p=0.2869$ ).

The red and black banded replicas were attacked significantly more in edge sympatric habitats in 2019 (contingency analysis, $\chi^{2}=15.088, p=0.0017$ ), but this was not found in

211 allopatric habitats (contingency analysis, $\chi^{2}=4.714, p=0.1940$ ). In 2018, color pattern was not 212 associated with attack rate in either habitat (contingency analyses; edge sympatry $\chi^{2}=1.761, p=$ 2130.6234 ; allopatry $\left.\chi^{2}=0.876, p=0.8312\right)$.

215 clay replicas. In 2019, the best statistical model included transect, sympatry, and the presence of 216 red (no interaction) (Table 1, also see electronic supplementary material Table S2). Two 217 statistical models fell within two AICc units of the best statistical model, and both contained 218 sympatry as a term. These statistical models also included individual color pattern without an 219 interaction, as well as the presence of red with an interaction. Furthermore, we found that in 2202019 both the presence of red and the presence of bands increased attack rates in edge sympatric 221 habitats, with a similar pattern in allopatric habitats (Fig. 4, see also electronic supplementary 222 material Table S4). In 2018, the null model was the best model (Table 2, also see electronic 223 supplementary material, Table S3). All of the statistical models that fell within two AICc units of 224 the null model had only one additional term after transect: sympatry or the presence of white or 
225 red. The impact of signal components on attack rates did not differ between edge sympatric and 226 allopatric habitats in 2018.

\section{Discussion}

Contrary to expectations, we found that coral snake patterns did not confer a protective

229 advantage in either edge sympatry or allopatry in the montane tropics of Honduras. Replicas

230 without mimicry components almost always had lower attack rates than those with mimicry

231 components, regardless of both year and whether they were placed in an edge sympatric habitat

232 or an allopatric habitat. We also found that replicas with red or bands had higher attack rates than

233 those without in 2019 in areas of edge sympatry. These results are in contrast to previous

234 findings, where both brown replicas and replicas with imprecise mimetic patterns were attacked

235 more than precise mimetic replicas in sympatric regions (including edge sympatric) (Brodie III,

236 1993; Brodie III \& Janzen, 1995; Kikuchi \& Pfennig, 2010; Pfennig et al., 2001). In addition, we

237 found that patterns of attacks on replicas varied between years, which could be caused by

238 temporal heterogeneity or negative frequency-dependent selection (Akcali et al., 2018; Cox \&

239 Davis Rabosky, 2013; Holmes et al., 2017). Our research supports the idea that mimicry

240 dynamics might differ in the montane tropics compared to temperate habitats.

In temperate regions, mimetic patterns can incur a fitness cost that varies between

242 allopatric regions with different local mimics, implying that even between allopatric populations

243 in similar habitats there can be differences in patterns of selection (Pfennig et al., 2007). In one

244 previous study, predators in the southeastern United States differentially attacked replicas

245 depending on whether they were in deep sympatry or edge sympatry (Harper \& Pfennig, 2007).

246 Those predators avoided both poor and accurate mimetic phenotypes in areas of deep sympatry,

247 but they avoided only accurate mimics in edge sympatry. In studies taking place in the lowland 
248 tropics, avian predators attacked brown replicas more often than tricolored or red-and-black

249 banded replicas (Brodie III, 1993; Brodie III \& Janzen, 1995). In our study, we did not find that

250 predators avoided the more accurate mimetic phenotypes, but rather, the replicas with

251 phenotypes most closely resembling those of coral snakes (tricolored and red-and-black banded)

252 were often those attacked most. These results support the idea that in areas where coral snakes

253 are rare or absent (such as the range edge and close allopatry of our study areas), mimetic

254 phenotypes may not confer as much of an advantage as in areas where coral snakes are common

255 (such as the lowland tropics), which is consistent with classic Batesian mimicry theory (Brodie

256 III \& Janzen, 1995; Pfennig \& Mullen, 2010; Quicke, 2017; Ruxton et al., 2004). Yet why

257 multiple aposematic species of models and mimics may persist in our study area, given the

258 fitness costs that we have demonstrated, is a bit more perplexing. There are three primary, non-

259 mutually exclusive reasons why mimicry could be maintained in the face of apparent

260 maladaptation: 1) there is an interplay of aposematic coloration and behavior and thus mimetic

261 phenotypes are not actually maladaptive, 2) mimetic phenotypes are indeed maladaptive but may

262 be maintained by gene flow and/or 3) the apparent maladaptation of mimetic phenotypes

263 fluctuates temporally, likely due to negative frequency-dependent selection (Pfennig \& Mullen,

264 2010).

First, the behavioral component of coral snake mimicry might reinforce and strengthen

266 the avoidance of mimetic patterns. Coral snakes display stereotyped coiling and thrashing

267 behavior when threatened, and thus behavior is an integrated part of their antipredator display

268 (Brown et al., 2020; Davis Rabosky et al., 2020; Titcomb et al., 2014). The effect of interacting

269 coloration and behavior on predator avoidance has been documented in other systems: for 
271 whereas stationary replicas of red aposematic frogs were attacked significantly more than when

272 moving (Paluh et al., 2014). These findings suggest that movement and behavior may play an

273 important role in selection for both cryptic and aposematic individuals (Bateman et al., 2017).

274 Thus, while the use of clay replicas provides a useful tool for studying predation, a limitation of

275 the method is that it is unable to capture the effects of behavior, and it is not known whether a

276 stationary clay replica is recognized as a snake by a bird or mammalian predator (Bateman et al.,

277 2017). Our results might suggest that there may also be variation in how important movement is

278 in relation to prey selection by predators. In addition, other research has suggested that in range

279 edges where models may be rare, selection for avoidance of aposematic phenotypes may be

280 weaker and thus behavior could play an important role in reinforcing color signals (Charlesworth

281 \& Charlesworth, 1975).

Second, mimetic phenotypes could indeed be maladaptive in areas of edge sympatry and 283 allopatry, but migration and gene flow from regions where mimicry is adaptive (areas of deep 284 sympatry at lower elevations) maintain the presence of mimetic phenotypes (Ries \& Mullen, 285 2008). Indeed, coral snake mimics are known to migrate from areas of sympatry to allopatry in 286 temperate systems (Harper \& Pfennig, 2008). In and around Cusuco National Park, it is plausible 287 that coral snake mimics could migrate from areas of high coral snake density (e.g., lowlands) to 288 areas where coral snakes are uncommon or absent (e.g., montane regions), thus influencing our 289 study. Similarly, range expansion of mimics may create newer areas of edge sympatry or 290 allopatry where predators have not yet evolved or learned avoidance (Pfennig \& Mullen, 2010). 291 Thus, immigration and gene flow of mimics between high elevations without coral snakes and 292 low elevations with coral snakes could allow mimicry to persist at high elevations. 
Finally, mimicry might be maintained despite a fitness cost through temporally fluctuating

selection, such as negative frequency-dependent selection. We found evidence of temporal variation in predation rates on coral snake color patterns, although we cannot rule out minor variation in experimental implementation between years that might contribute to this perceived temporal variation. Many mimicry systems are influenced by frequency-dependent selection, including frogs, snails, butterflies, and snakes (Holmes et al., 2017; Ries \& Mullen, 2008). Because this type of selection allows rare phenotypes to increase in frequency in the population, the preferred target of predators also changes over time (Holmes et al., 2017; Pfennig et al., 2007). Frequency-dependent selection has been shown to play an important role in Batesian mimicry (Akcali et al., 2018; Cox \& Davis Rabosky, 2013; Finkbeiner et al., 2018; Holmes et al., 2017; Pfennig et al., 2001; Pfennig \& Mullen, 2010). In areas where coral snake models are uncommon or absent and relatively harmless mimics are abundant, predators may learn or evolve a preference for conspicuous prey (Pfennig et al., 2007; Pfennig \& Mullen, 2010). Over time, this may reduce the relative abundance of mimics and thereby decrease the ratio of mimics to models, which eventually leads to selection for the avoidance of mimetic phenotypes by predators. As the mimic to model ratio then increases once again, predators may re-learn or reevolve the preference for conspicuous mimetic color patterns. Such a negative frequencydependent cycle could result in a dynamic relationship between the frequencies of different mimetic phenotypes, causing temporal heterogeneity in the phenotypes most selected against (Cox \& Davis Rabosky, 2013). Our study may have taken place at the point in the cycle where mimetic phenotypes are maladaptive, yet they are able to persist because the phenotype is favored when rare. In addition, it is important to note that the presence of learned and innate avoidance, as well as the predator assemblages present at a given time, would likely impact the 
dynamics of frequency-dependent selection (Akcali et al., 2018). For example, naïve juvenile motmots and great kiskadees innately avoid coral snake patterns, yet puffbirds and adult motmots have been documented to consume coral snakes (Smith, 1969; Smith, 1975; Smith, 1977). While predators likely have a combination of innate and learned avoidance, learned avoidance would lead to a shorter period of the negative frequency-dependent cycle than innate avoidance because innate avoidance relies on intergenerational processes.

Although we found that mimetic phenotypes did not confer a fitness advantage and may actually lead to decreased survivorship, some of our results were consistent with previous research on coral snake mimicry. In areas of edge sympatry, red and black replicas were attacked more often than tricolored replicas, but the opposite was true in areas of allopatry. This result could indicate that it is beneficial to be a precise mimic in areas where the model is rare (but present), but protection breaks down farther from the model's range, which is consistent with previous findings that predators avoid precise mimics over poor mimics in edge sympatry (Harper \& Pfennig, 2007). Studies using museum specimens have also found differences in mimetic precision in relation to sympatry and allopatry (Akcali \& Pfennig, 2014; Akcali \& Pfennig, 2017; Harper \& Pfennig, 2007). Within a single species, the most precise mimics to a local model were found at the edge of the model's range rather than in deep sympatry (Harper \& Pfennig, 2007). Nevertheless, other studies have found that mimetic precision differs between species, and in some cases the most precise mimics have been found in areas of allopatry (Akcali \& Pfennig, 2014; Akcali \& Pfennig, 2017).

Our data suggest that coral snake mimicry may not provide an advantage in areas where coral snakes have low abundance (despite having the high diversity of the tropics), such as in edge sympatry and allopatry. Seemingly maladaptive mimicry might persist because of an 
339 interaction between aposematism and defensive behavior that is unable to be captured in a clay

340 replica study, gene flow and immigration of both mimics and predators from areas where

341 mimicry is adaptive, temporal fluctuation in selection such as negative frequency-dependent

342 selection, or a combination of these processes. Our work highlights the importance of the

343 interactions among color patterns, model sympatry, and temporal variation in understanding

344 predation on coral snakes and their mimics. Long-term studies that characterize predation of

345 mimics in locations from deep sympatry to deep allopatry with models would be ideal to further

346 understand the complex nature of how sympatry and allopatry affect selection on mimicry.

\section{Acknowledgements}

We thank Mairéad Corr, Maddy Blunt, Georgina Davey, Hunter McCall, Rodrigo Morales, Harry Pym-Davis, and Chris Phipps for field assistance. Declan Crace and Tom Martin were

350 instrumental in the design and implementation of this research. We thank the Department of

351 Biology at Georgia Southern University and Operation Wallacea for supporting this project. Our

352 sincere gratitude is extended to Lance McBrayer, Adam Rosso, Albert Chung, and Scott Meyer 353 for advice during this project.

\section{Declarations}

355 Funding: This work was supported by Operation Wallacea and Georgia Southern University.

356 Conflict of Interest Statement: The authors have no conflict of interest to declare.

357 Ethics Approval: Not applicable

358 Consent to participate: Not applicable

359 Consent for publication: Not applicable

360 Availability of data and material: Data will be deposited at Dryad upon acceptance.

361 Code availability: R code used for attack analyses available at

362 https://figshare.com/articles/software/Coral_snake_mimicry_attack_analyses/14531775 


\section{Authors' contributions:}

364 LW participated in the design of the study, collected field data, carried out statistical analyses, 365 and drafted the manuscript; GL participated in the design of the study, aided in field work, and 366 revised the manuscript; JDC participated in the design of the study, collected field data, and 367 revised the manuscript; EH aided in statistical analyses and critically revised the manuscript, CC 368 conceived of the study, designed the study, coordinated the study, and critically revised the 369 manuscript. All authors gave final approval for publication and agree to be held accountable for 370 the work performed therein. 
373

374

375

376

377

378

379

380

381

382

383

384

385

386

387

388

389

390

391

392

393

394

Akcali, C., Kikuchi, D. and Pfennig, D. (2018) Coevolutionary arms races in Batesian mimicry? A test of the chase-away hypothesis. Biological Journal of the Linnean Society, 124: 668676.

Akcali, C.K. and Pfennig, D.W. (2014) Rapid evolution of mimicry following local model extinction. Biol Lett, 10.

Akcali, C.K. and Pfennig, D.W. (2017) Geographic variation in mimetic precision among different species of coral snake mimics. J Evol Biol, 30: 1420-1428.

Alliance, A.S. 2019. Spike-thumb Frog, Plectrohyla dasypus. Amphibian Survival Alliance.

Arbuckle, K. and Speed, M.P. (2015) Antipredator defenses predict diversification rates. Proc Natl Acad Sci U S A, 112: 13597-13602.

Bateman, P.W., Fleming, P.A. and Wolfe, A.K. (2017) A different kind of ecological modelling: the use of clay model organisms to explore predator-prey interactions in vertebrates. Journal of Zoology, 301: 251-262.

Bates, D., Maechler, M., Bolker, B. and Walker, S. (2015) Fitting Linear Mixed-Effects Models Using lme4. Journal of Statistical Software, 67: 1-48.

Brodie III, E. (1993) Differential Avoidance of Coral Snake Banded Patterns by Free-Ranging Avian Predators in Costa Rica. Evolution, 47: 227-235.

Brodie III, E. and Janzen, F.J. (1995) Experimental Studies of Coral Snake Mimicry: Generalized Avoidance of Ringed Snake Patterns by Free-Ranging Avian Predators. Functional Ecology, 9.

Brown, T. and Arrivillaga, C.(2017) Herpetofauna of Cusuco National Park, Honduras: Operation Wallacea. 
Brown, T.W., Barazowski, M.B. and Lonsdale, G. (2020) Defensive tail-curling and headmimicking behavior in a variable coralsnake, Micrurus diastema (Squamata: Elapidae) in Cusuco National Park, Honduras. International Reptile Conservation Foundation, 27: 231-232.

Charlesworth, D. and Charlesworth, B. (1975) Theoretical genetics of batesian mimicry I. Single-locus models. Journal of Theoretical Biology, 55: 283-303.

Cox, C.L. and Davis Rabosky, A.R. (2013) Spatial and temporal drivers of phenotypic diversity in polymorphic snakes. Am Nat, 182: E40-57.

Davis Rabosky, A.R., Cox, C.L., Rabosky, D.L., Title, P.O., Holmes, I.A., Feldman, A. and McGuire, J.A. (2016) Coral snakes predict the evolution of mimicry across New World snakes. Nat Commun, 7: 11484.

Davis Rabosky, A.R., Larson, J.G., Danforth, S.M. and Moore, T.Y. (2020) A Quantitative Analysis of Micrurus Coral Snakes Reveals Unexpected Variation in Stereotyped AntiPredator Displays Within a Mimicry System. Integrative Organismal Biology, 2.

Endler, J.A.(1986) Natural Selection in the Wild. Princeton, New Jersey, USA: Princeton University Press.

Finkbeiner, S.D., Salazar, P.A., Nogales, S., Rush, C.E., Briscoe, A.D., Hill, R.I., Kronforst, M.R., Willmott, K.R. and Mullen, S.P. (2018) Frequency dependence shapes the adaptive landscape of imperfect Batesian mimicry. Proc Biol Sci, 285.

Freeman, S. and Herron, J.C. 2004. Ch 3: Darwinian Natural Selection. In Evolutionary Analysis.

Greene, H.W. and McDiarmid, R.W. (1981) Coral snake mimicry: does it occur? Science, 213: 1207-1212. 
Ham, A.D., Ihalainen, E., Lindström, L. and Mappes, J. (2006) Does colour matter? The importance of colour in avoidance learning, memorability and generalisation. Behavioral Ecology and Sociobiology, 60: 482-491.

Harper, G.R., Jr. and Pfennig, D.W. (2008) Selection overrides gene flow to break down maladaptive mimicry. Nature, 451: 1103-1106.

Harper, G.R. and Pfennig, D.W. (2007) Mimicry on the edge: why do mimics vary in resemblance to their model in different parts of their geographical range? Proc Biol Sci, 274: 1955-1961.

Hengeveld, R. and Haeck, J. (1982) The Distribution of Abundance. I. Measurements. Journal of biogeography, 9: 303-316.

Hinman, K.E., Throop, H., L Adams, K., J Dake, A., McLauchlan, K. and J McKone, M. (1997) Predation by free-ranging birds on partial coral snake mimics: the importance of ring width and color. Society for the Study of Evolution, 51: 1011-1014.

Holmes, I.A., Grundler, M.R. and Davis Rabosky, A.R. (2017) Predator Perspective Drives Geographic Variation in Frequency-Dependent Polymorphism. Am Nat, 190: E78-E93.

Joron, M. and Mallet, J.L.B. (1998) Diversity in mimicry: paradox or paradigm? Trends in Ecology \& Evolution, 13: 461-466.

Kikuchi, D.W. and Pfennig, D.W. (2010) Predator cognition permits imperfect coral snake mimicry. Am Nat, 176: 830-834.

Kikuchi, D.W. and Pfennig, D.W. (2013) Imperfect mimicry and the limits of natural selection. The Quarterly review of biology, 88: 297.

Kleisner, K. and Saribay, S.A. (2018) The Dual Nature of Mimicry: Organismal Form and Beholder's Eye. Biosemiotics. 
441 Kuchta, S.R. (2005) Experimental Support for Aposematic Coloration in the Salamander

442

443

444

445

446

447

448

449

450

451

452

453

454

455

456

457

458

459

460

461

462

463
Ensatina eschscholtzii xanthoptica: Implications for Mimicry of Pacific Newts. Copeia, 2005: 265-271.

Leimar, O., Enquist, M. and Sillen-Tullberg, B. (1986) Evolutionary Stability of Aposematic Coloration and Prey Unprofitability: A Theoretical Analysis. The American Naturalist, 128: 469-490.

Lindstedt, C., Eager, H., Ihalainen, E., Kahilainen, A., Stevens, M. and Mappes, J. (2011) Direction and strength of selection by predators for the color of the aposematic wood tiger moth. Behavioral Ecology, 22: 580-587.

Lindström, L., Alatalo, R.V. and Mappes, J. (1997) Imperfect Batesian mimicry-the effects of the frequency and the distastefulness of the model. Proceedings of the Royal Society B: Biological Sciences, 264: 149-153.

Mallet, J. and Turner, J. (1997) Biotic drift or the shifting balance — Did forest islands drive the diversity of warningly coloured butterflies? Philosophical Transactions of the Royal Society B: Biological Sciences, 351: 262-280.

Mappes, J. and Alatalo, R.V. (1997) Batesian Mimicry and Signal Accuracy. Evolution, 51: 2050-2053.

Mappes, J., Marples, N. and Endler, J.A. (2005) The complex business of survival by aposematism. Trends Ecol Evol, 20: 598-603.

Mazerolle, M.J. 2019. AICcmodavg: Model selection and multimodel inference based on (Q)AIC(c).

McCranie, J.R. and Savage, J.M.(2011) The Snakes of Honduras: Systematics, Distribution, and Conservation: Society for the Study Of Amphibians. 
Owen, R.E. and Owen, A.R.G. (1984) Mathematical paradigms for mimicry: Recurrent sampling. Journal of Theoretical Biology, 109: 217-247.

Paluh, D.J., Hantak, M.M. and Saporito, R.A. (2014) A Test of Aposematism in the Dendrobatid Poison FrogOophaga pumilio: The Importance of Movement in Clay Model Experiments. Journal of Herpetology, 48: 249-254.

Pfennig, D.W. (2016) Evolutionary biology: To mimicry and back again. Nature, 534: 184-185.

Pfennig, D.W., Harcombe, W.R. and Pfennig, K.S. (2001) Frequency-dependent Batesian mimicry. Nature, 410: 323.

Pfennig, D.W., Harper, G.R., Brumo, A.F., Harcombe, W.R. and Pfennig, K.S. (2007) Population differences in predation on Batesian mimics in allopatry with their model: selection against mimics is strongest when they are common. Behavioral Ecology and Sociobiology, 61: 505-511.

Pfennig, D.W. and Mullen, S.P. (2010) Mimics without models: causes and consequences of allopatry in Batesian mimicry complexes. Proc Biol Sci, 277: 2577-2585.

Pough, F.H. (1988) Mimicry of Vertebrates: Are the Rules Different? The American Naturalist, 131: S67-S102.

Quicke, D.L.J.(2017) Mimicry, crypsis, masquerade and other adaptive resemblances: Hoboken, NJ : Wiley Blackwell, 2017.

R Core Team. 2020. R: A Language and Environment for Statistical Computing. Vienna, Austria: R Foundation for Statistical Computing.

Ries, L. and Mullen, S.P. (2008) A rare model limits the distribution of its more common mimic: a twist on frequency-dependent Batesian mimicry. Evolution, 62: 1798-1803. 
05

Ruxton, G., Allen, W., N. Sherratt, T. and Speed, M.(2004) Avoiding Attack: The Evolutionary Ecology of Crypsis, Aposematism, and Mimicry. New York: Oxford University Press.

Savage, J.M. and Slowinski, J.B. (1992) The colouration of the venomous coral snakes (family Elapidae) and their mimics (families Aniliidae and Colubridae). Biological Journal of the Linnean Society, 45: 235-254.

Smith, N.G. (1969) Avian Predation of Coral Snakes. Copeia, 1969: 402-404.

Smith, S.M. (1975) Innate Recognition of Coral Snake Pattern by a Possible Avian Predator. Science, 187: 759.

Smith, S.M. (1977) Coral-snake pattern recognition and stimulus generalisation by naive great kiskadees (Aves: Tyrannidae). Nature, 265: 535-536.

Stevens, M. and Ruxton, G.D. (2012) Linking the evolution and form of warning coloration in nature. Proceedings of the Royal Society B: Biological Sciences, 279: 417-426.

Titcomb, G., Kikuchi, D. and Pfennig, D. (2014) More than mimicry? Evaluating scope for flicker-fusion as a defensive strategy in coral snake mimics. Current Zoology, 60: 123130.

Townsend, J.H. and Wilson, L.D.(2008) The Amphibians \& Reptiles of Cusuco National Park, Honduras. Salt Lake City, Utah: Bibliomania!

Yamauchi, A. (1993) A population dynamic model of Batesian mimicry. Researches on Population Ecology, 35: 295-315. 
Appendices

Extended study site description

The study location in Cusuco National Park, Honduras, comprises a tropical, montane

512 environment that includes both sympatric and allopatric populations of coral snakes and coral 513 snake mimics (Townsend \& Wilson, 2008). The park is a protected area located in the

514 Merendón Mountains of northwest Honduras and is roughly 200 square km in area, with an 515 elevational range of approximately 115 m to just over 2200 m (Alliance, 2019; Brown \& 516 Arrivillaga, 2017). Cusuco National Park spans a variety of forest types including cloud forest 517 (distinguished by frequent cloud cover), dwarf forest (distinguished by high elevations, small 518 trees, and increased number of epiphytes), and forest fringes (distinguished by little to no tree 519 cover). These habitats are predominately broad-leaf, pine, or mixed forests (Brown \& 520 Arrivillaga, 2017; Townsend \& Wilson, 2008). There are two species of coral snakes found in 521 the park: Micrurus diastema and Micrurus nigrocinctus. Both of these species exhibit tricolor 522 patterns of red, black, and white/yellow, although both have also been found to exhibit bicolor a 523 red and black morph (Brown \& Arrivillaga, 2017; Townsend \& Wilson, 2008). In addition, there 524 are nine species of colubroid snakes found in the park that are considered coral snake mimics: 525 Geophis nephodrymus, Lampropeltis abnorma, Ninia sebae, Oxyrhopus petolarius, Pliocercus 526 elapoides, Scaphiodontophis annulatus, Scolecophis atrocinctus, Sibon dimidiatus, and 527 Tropidodipsas sartorii (Brown \& Arrivillaga, 2017; Townsend \& Wilson, 2008). All of these 528 species are considered mimics because at least one morph in each species has banded patterns of 529 black, red, and/or white. They range from tricolor mimics such as P. elapoides and L. abnorma 
530 to bicolor red and black (some G. nephodrymus) or white/yellow/orange and black (T. sartorii)

531 (Brown \& Arrivillaga, 2017; McCranie \& Savage, 2011; Townsend \& Wilson, 2008).

532 Extended transect description

In order to assess predation rates on various mimetic and non-mimetic color patterns, we

534 analyzed the number of attacks on clay replicas. We constructed these non-toxic, pre-colored 535 clay replicas to have patterns loosely based on snakes found in the park. Replicas were either 536 cryptic (brown) or mimetic (white-and-black banded, red-and-black banded, or tri-colored with 537 red, white, and bands) (Figure S1a).

We placed clay replicas in groups of four, hereafter referred to as a tetrad, which included 539 one of each replica color pattern. Over a span of eight weeks from June to August in 2018 and in 5402019 , we arranged the tetrads along transects at varying elevations within the park (Table S1).

541 Transects higher than $1800 \mathrm{~m}$ in elevation were classified as allopatric, and those lower than

$5421800 \mathrm{~m}$ were classified as edge sympatric. Of the nine transects in 2018 , three were allopatric and 543 six were edge sympatric. Of the 18 transects in 2019 , three were allopatric and 15 were edge 544 sympatric. There were fewer allopatric transects because there was much less space to lay out 545 transects in the higher elevations of the mountaintop. Each transect contained seven (in 2018) or 546 ten (in 2019) branches, spaced approximately ten meters apart, with one tetrad per branch

547 (Figure S1a). We placed each replica within a tetrad at least three meters apart from other 548 replicas in the tetrad. The order of the replicas within each tetrad was randomly determined using 549 a random number generator. We calculated an ideal sample size for the total number of clay 550 replicas on transects for 2019 through a power analysis based on the attack data from 2018 . We 551 left replicas out on transects for a period of two weeks and checked them every three to four days 552 for marks of predation (e.g. distinct beak, bite, or claw marks). Once checked, replicas were 
553 smoothed over and placed in the same spot. If a replica was attacked more than once during the

554 two weeks, only one attack was counted. Each instance of attack was scored for type of predator

555 (bird, mammal, or unidentifiable) and recorded. Different observers checked and scored the

556 replicas from year to year.

We analyzed the data using a combination of mixed effect models compared with model

559 selection and contingency analyses. The mixed effects models and model selection demonstrated 560 whether sympatry and color pattern had meaningful effects on attack rates, and contingency 561 analyses were used to estimate differences in predation rates between clay replica types, habitats, 562 and years. To avoid missing patterns of selection that could occur by discarding ambiguous 563 attack marks, we combined bird and mammal attacks into an overall "attacked" category. We 564 performed contingency analyses in JMP v 13.1.0 (SAS Statistical Institute, Cary, NC, USA) with 565 all samples pooled regardless of transect. We created logistic mixed effect models in R and 566 compared them using small sample size-corrected Akaike information criterion (AICc) values to 567 determine which statistical models were most effective in predicting attack rates (Bates et al., 568 2015; Mazerolle, 2019; R Core Team, 2020). The response variable for these statistical models 569 was whether a replica was attacked or not attacked at any point during the two week period. The 570 null models for each year included only transect as a random effect. The remaining statistical 571 models included transect as a random effect as well as all potential combinations of: level of 572 sympatry, one of the five color variables, and interaction terms. 
577 Alliance, A.S. (2019) Spike-thumb Frog, Plectrohyla dasypus. Amphibian Survival Alliance.

578 Bates, D., Maechler, M., Bolker, B. and Walker, S. (2015) Fitting Linear Mixed-Effects Models

$579 \quad$ Using lme4. Journal of Statistical Software, 67: 1-48.

580 Brown, T. and Arrivillaga, C.(2017) Herpetofauna of Cusuco National Park, Honduras:

$581 \quad$ Operation Wallacea.

582 Mazerolle, M.J. 2019. AICcmodavg: Model selection and multimodel inference based on $583 \quad$ (Q)AIC(c).

584 McCranie, J.R. and Savage, J.M.(2011) The Snakes of Honduras: Systematics, Distribution, and 585 Conservation: Society for the Study Of Amphibians.

586 R Core Team. 2020. R: A Language and Environment for Statistical Computing. Vienna, Austria: R Foundation for Statistical Computing.

588 Townsend, J.H. and Wilson, L.D.(2008) The Amphibians \& Reptiles of Cusuco National Park, $589 \quad$ Honduras. Salt Lake City, Utah: Bibliomania! 


\section{Supplemental Tables}

Table S1. Data associated with each transect along which clay snake replicas were set out and monitored. Coral snake sympatry or allopatry for each transect was determined by the transect's elevation.

\begin{tabular}{|c|c|c|}
\hline$\underline{\text { Year }}$ & $\underline{\text { Elevation }(\mathrm{m})}$ & $\begin{array}{c}\text { Coral snake } \\
\text { Sympatry/Allopatry } \\
\end{array}$ \\
\hline 2018 & 1598 & sympatric \\
\hline 2018 & 1617 & sympatric \\
\hline 2018 & 1617 & sympatric \\
\hline 2018 & 2017 & allopatric \\
\hline 2018 & 2013 & allopatric \\
\hline 2018 & 1766 & sympatric \\
\hline 2018 & 1358 & sympatric \\
\hline 2018 & 1250 & sympatric \\
\hline 2018 & 1244 & sympatric \\
\hline 2019 & 1598 & sympatric \\
\hline 2019 & 1607 & sympatric \\
\hline 2019 & 1618 & sympatric \\
\hline 2019 & 1653 & sympatric \\
\hline 2019 & 1617 & sympatric \\
\hline 2019 & 1624 & sympatric \\
\hline 2019 & 1995 & allopatric \\
\hline 2019 & 1766 & sympatric \\
\hline 2019 & 1998 & allopatric \\
\hline 2019 & 1762 & sympatric \\
\hline 2019 & 1781 & sympatric \\
\hline 2019 & 1826 & allopatric \\
\hline 2019 & 1270 & sympatric \\
\hline 2019 & 1252 & sympatric \\
\hline 2019 & 1244 & sympatric \\
\hline 2019 & 1277 & sympatric \\
\hline 2019 & 1234 & sympatric \\
\hline 2019 & 1354 & sympatric \\
\hline
\end{tabular}


Table S2. Results of mixed effect model comparison using small sample size-corrected Akaike Information Criterion (AICc). Linear models were created to predict whether a clay replica in 2019 was attacked using the following terms: the transect on which it was located, if it was in sympatry, a color variable (the individual color pattern, the presence of white, the presence of red, the presence of bands, or whether it was tricolor), and an interaction between sympatry and the color variable. $K$ is the number of parameters and $\triangle \mathrm{AICc}$ is the difference between that statistical model and the best model. Statistical models within $2 \Delta \mathrm{AICc}$ units of the top model are bolded

*indicates random effect and ** indicates an interaction variable was included between the two variables

\begin{tabular}{|c|c|c|c|c|c|c|c|c|}
\hline$K$ & AICc & $\Delta \mathrm{AICc}$ & $\begin{array}{c}\text { AICc } \\
\text { Weight }\end{array}$ & $\begin{array}{c}\text { Log- } \\
\text { likelihood } \\
\end{array}$ & term 1 & term 2 & term 3 & term 4 \\
\hline 4 & 824.6768 & $\mathbf{0}$ & 0.404193 & -408.31 & transect* & sympatry & red & -- \\
\hline 6 & 825.3787 & 0.701893 & 0.28456 & -406.63 & transect* & sympatry & $\begin{array}{c}\text { individual } \\
\text { pattern }\end{array}$ & -- \\
\hline 5 & 826.6367 & 1.959888 & 0.151707 & -408.276 & transect* & sympatry $* *$ & red $^{* *}$ & interaction \\
\hline 9 & 827.6545 & 2.977695 & 0.091199 & -404.7 & transect* & sympatry** & $\begin{array}{l}\text { individual } \\
\text { pattern** }\end{array}$ & interaction \\
\hline 4 & 829.2339 & 4.557145 & 0.041402 & -410.589 & transect* & sympatry & bands & -- \\
\hline 5 & 831.2141 & 6.537345 & 0.015382 & -410.565 & transect* & sympatry** & bands** & interaction \\
\hline 3 & 834.7732 & 10.0964 & 0.002595 & -414.37 & transect* & sympatry & & \\
\hline 5 & 835.1136 & 10.43682 & 0.002189 & -412.515 & transect* & sympatry** & tricolor** & interaction \\
\hline 3 & 835.5943 & 10.91752 & 0.001721 & -414.78 & transect* & red & -- & -- \\
\hline 5 & 836.0688 & 11.39206 & 0.001358 & -412.992 & transect* & sympatry** & white** & interaction \\
\hline 5 & 836.2869 & 11.61017 & 0.001218 & -413.101 & transect* & $\begin{array}{c}\text { individual } \\
\text { pattern }\end{array}$ & & -- \\
\hline 4 & 836.3954 & 11.7186 & 0.001153 & -414.17 & transect* & sympatry & tricolor & -- \\
\hline 4 & 836.4445 & 11.76768 & 0.001125 & -414.194 & transect* & sympatry & white & -- \\
\hline 3 & 840.1477 & 15.47089 & 0.000177 & -417.057 & transect* & bands & -- & -- \\
\hline 2 & 845.6788 & 21.00198 & $1.11 \mathrm{E}-05$ & -420.831 & transect* & -- & -- & -- \\
\hline 3 & 847.2958 & 22.61905 & 4.95E-06 & -420.631 & transect* & tricolor & -- & -- \\
\hline 3 & 847.3449 & 22.6681 & 4.83E-06 & -420.656 & transect* & white & -- & -- \\
\hline
\end{tabular}


Table S3. Results of mixed effect model comparison using small sample size-corrected Akaike Information Criterion (AICc). Linear models were created to predict whether a clay replica in 2018 was attacked using the following terms: the transect on which it was located, if it was in sympatry with coral snakes, a color variable (the individual color pattern, the presence of white, the presence of red, the presence of bands, or whether it was tricolor), and an interaction between sympatry and the color variable. $K$ is the number of parameters and $\triangle \mathrm{AICc}$ is the difference between that statistical model and the best model. Statistical models within $2 \Delta \mathrm{AICc}$ units of the top model are bolded.

*indicates random effect and $* *$ indicates an interaction variable was included between the two variables

\begin{tabular}{|c|c|c|c|c|c|c|c|c|}
\hline K & AICc & $\triangle \mathrm{AICc}$ & $\begin{array}{c}\text { AICc } \\
\text { Weight }\end{array}$ & $\begin{array}{c}\text { Log- } \\
\text { likelihood }\end{array}$ & term 1 & term 2 & term 3 & term 4 \\
\hline 2 & 341.8013 & 0 & 0.223916 & -168.877 & transect* & -- & -- & -- \\
\hline 3 & 343.1601 & 1.358776 & 0.113509 & -168.532 & transect* & sympatry & -- & -- \\
\hline 3 & 343.4256 & 1.624319 & 0.099396 & -168.664 & transect* & red & -- & -- \\
\hline 3 & 343.4256 & 1.624319 & 0.099396 & -168.664 & transect* & white & -- & -- \\
\hline 3 & 343.8442 & 2.042923 & 0.080625 & -168.874 & transect* & tricolor & -- & -- \\
\hline 3 & 343.8442 & 2.042923 & 0.080625 & -168.874 & transect* & bands & -- & -- \\
\hline 4 & 344.8011 & 2.999781 & 0.049968 & -168.32 & transect* & sympatry & white & -- \\
\hline 4 & 344.8011 & 2.999781 & 0.049968 & -168.32 & transect* & sympatry & red & -- \\
\hline 5 & 345.202 & 3.400738 & 0.040891 & -167.479 & transect* & sympatry & white ${ }^{* *}$ & interaction \\
\hline 4 & 345.2196 & 3.418288 & 0.040533 & -168.529 & transect* & sympatry & tricolor & -- \\
\hline 4 & 345.2196 & 3.418288 & 0.040533 & -168.529 & transect* & sympatry** & bands & -- \\
\hline 5 & 346.3904 & 4.589131 & 0.022572 & -168.073 & transect* & sympatry** & tricolor** & interaction \\
\hline 5 & 346.8828 & 5.081478 & 0.017646 & -168.319 & transect* & sympatry** & $\operatorname{red}^{* *}$ & interaction \\
\hline 5 & 347.0318 & 5.230468 & 0.01638 & -168.394 & transect* & sympatry** & bands** & interaction \\
\hline 5 & 347.1333 & 5.332028 & 0.015569 & -168.445 & transect* & $\begin{array}{l}\text { individual } \\
\text { pattern }\end{array}$ & -- & -- \\
\hline 6 & 348.5427 & 6.741379 & 0.007695 & -168.1 & transect* & sympatry & individual pattern & -- \\
\hline 9 & 353.1259 & 11.32465 & 0.000778 & -167.191 & transect* & sympatry** & individual pattern** & interaction \\
\hline
\end{tabular}


Table S4. Results of contingency analyses to determine the statistical association between elements of replica color pattern and number of predatory attacks $(N=$ number of samples, $d f=$ degrees of freedom). * indicates significance

\begin{tabular}{|c|c|c|c|c|c|c|}
\hline $\begin{array}{c}\text { Color } \\
\text { variable }\end{array}$ & Year & Level of sympatry & $N$ & $\begin{array}{c}\chi^{2} \\
\text { statistic }\end{array}$ & $d f$ & p-value \\
\hline \multirow{4}{*}{$\begin{array}{l}\text { Color } \\
\text { Pattern }\end{array}$} & \multirow{2}{*}{2018} & Edge sympatry & 96 & 1.761 & 3 & 0.6234 \\
\hline & & Allopatry & 56 & 0.876 & 3 & 0.8312 \\
\hline & \multirow{2}{*}{2019} & Edge sympatry & 600 & 15.088 & 3 & $0.0017 *$ \\
\hline & & Allopatry & 120 & 4.714 & 3 & 0.1940 \\
\hline \multirow{4}{*}{ Red } & \multirow{2}{*}{2018} & Edge sympatry & 196 & 0.335 & 1 & 0.5625 \\
\hline & & Allopatry & 56 & 0.080 & 1 & 0.7778 \\
\hline & \multirow{2}{*}{2019} & Edge sympatry & 600 & 8.74 & 1 & $0.0031 *$ \\
\hline & & Allopatry & 120 & 3.367 & 1 & 0.0665 \\
\hline \multirow{4}{*}{ White } & \multirow{2}{*}{2018} & Edge sympatry & 196 & 1.342 & 1 & 0.2467 \\
\hline & & Allopatry & 56 & 0.717 & 1 & 0.3972 \\
\hline & \multirow{2}{*}{2019} & Edge sympatry & 600 & 1.537 & 1 & 0.2151 \\
\hline & & Allopatry & 120 & 1.212 & 1 & 0.2709 \\
\hline \multirow{4}{*}{ Bands } & \multirow{2}{*}{2018} & Edge sympatry & 196 & 0.028 & 1 & 0.8672 \\
\hline & & Allopatry & 56 & 0.239 & 1 & 0.6249 \\
\hline & \multirow{2}{*}{2019} & Edge sympatry & 600 & 5.096 & 1 & $0.0240 *$ \\
\hline & & Allopatry & 120 & 2.200 & 1 & 0.1380 \\
\hline \multirow{4}{*}{ Tricolored } & \multirow{2}{*}{2018} & Edge sympatry & 196 & 0.252 & 1 & 0.6159 \\
\hline & & Allopatry & 56 & 0.664 & 1 & 0.4152 \\
\hline & \multirow{2}{*}{2019} & Edge sympatry & 600 & 0.076 & 1 & 0.7831 \\
\hline & & Allopatry & 12 & 3.636 & 1 & 0.0565 \\
\hline
\end{tabular}




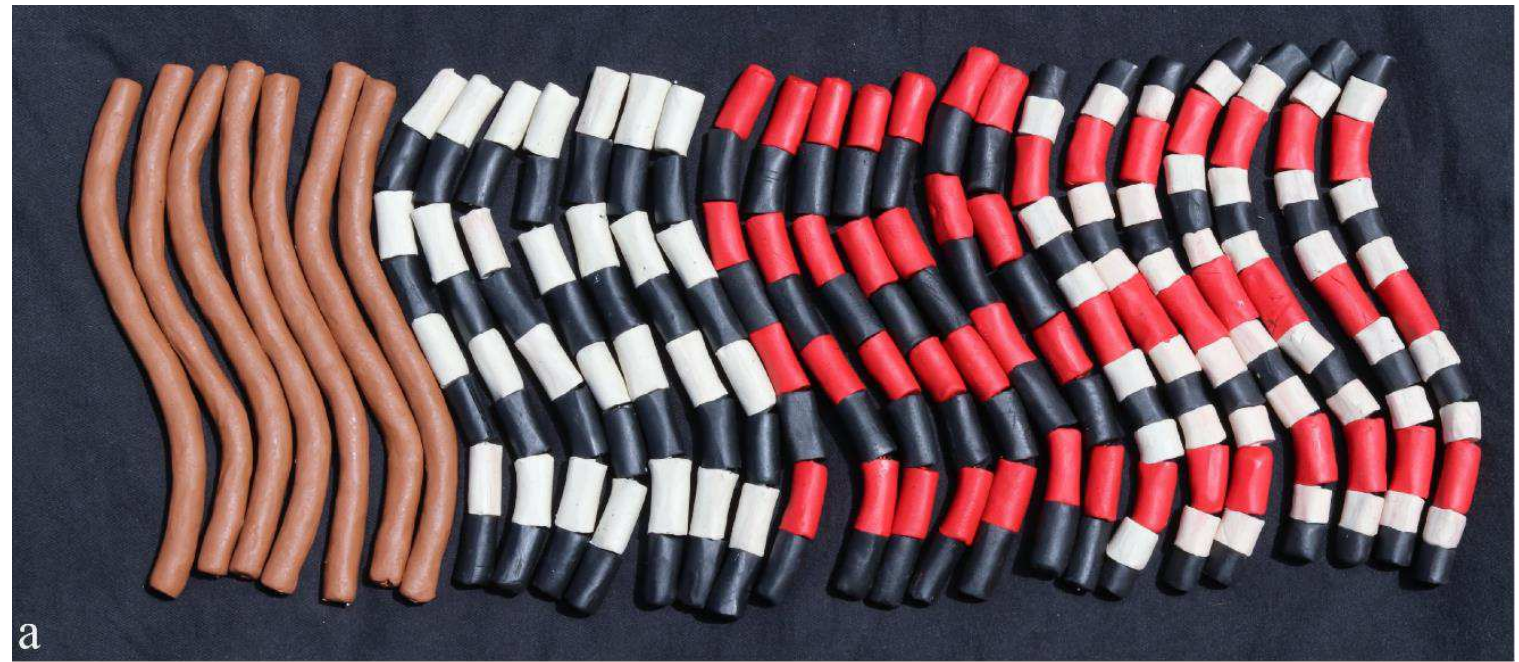

a

$\mathrm{b}$
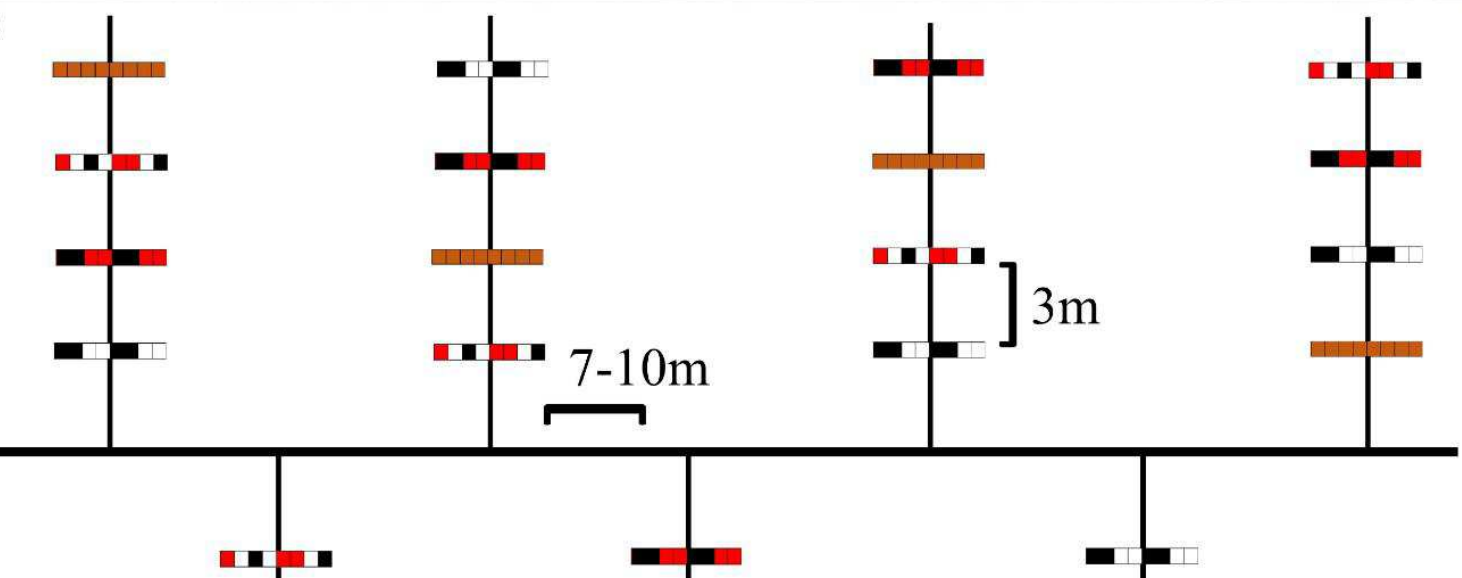

Figure S1. (a) Clay snake replicas showing four phenotypic color patterns: brown, white-andblack banded, red-and-black banded, and tricolor. Note that the latter three color patterns are considered mimetic, while the brown replicas are considered non-mimetic/cryptic. (b) Diagram

8 showing an example of how clay replicas were arranged along a portion of a transect. 


\section{Tables:}

Table 1: Results of mixed effect model comparison using small sample size-corrected Akaike Information Criterion (AICc). Linear models were created to predict whether a clay replica in 2019 was attacked using the following terms: the transect on which it was located, if it was in sympatry, a color variable (the individual color pattern, the presence of white, the presence of red, the presence of bands, or whether it was mimetic), and an interaction between sympatry and the color variable. $K$ is the number of parameters and $\triangle \mathrm{AICc}$ is the difference between that statistical model and the best model. Only statistical models within $2 \Delta \mathrm{AICc}$ units of the top model are included.

*indicates random effect and ** indicates an interaction variable was included between the two variables

\begin{tabular}{|c|c|c|c|c|c|c|c|c|}
\hline K & AICc & $\triangle \mathrm{AICc}$ & $\begin{array}{c}\text { AICc } \\
\text { Weight }\end{array}$ & $\begin{array}{c}\text { Log- } \\
\text { likelihood }\end{array}$ & term 1 & term 2 & term 3 & term 4 \\
\hline 4 & 824.6768 & 0 & 0.404193 & -408.31 & transect* & sympatry & red & -- \\
\hline 6 & 825.3787 & 0.701893 & 0.28456 & -406.63 & transect* & sympatry & $\begin{array}{l}\text { individual } \\
\text { pattern }\end{array}$ & -- \\
\hline 5 & 826.6367 & 1.959888 & 0.151707 & -408.276 & transect* & sympatry** & red** & interaction \\
\hline
\end{tabular}


Table 2. Results of mixed effect model comparison using small sample size-corrected Akaike Information Criterion (AICc). Linear models were created to predict whether a clay replica in 2018 was attacked using the following terms: the transect on which it was located, if it was in sympatry, a color variable (the individual color pattern, the presence of white, the presence of red, the presence of bands, or whether it was mimetic), and an interaction between sympatry and the color variable. $K$ is the number of parameters and $\triangle \mathrm{AICc}$ is the difference between that statistical model and the best model. Only statistical models within $2 \Delta \mathrm{AICc}$ units of the top model are included.

*indicates random effect

\begin{tabular}{|c|c|c|c|c|c|c|c|c|}
\hline$K$ & AICc & $\Delta \mathrm{AICc}$ & $\begin{array}{c}\text { AICc } \\
\text { Weight }\end{array}$ & $\begin{array}{c}\text { Log- } \\
\text { likelihood }\end{array}$ & term 1 & term 2 & term 3 & term 4 \\
\hline 2 & 341.8013 & 0 & 0.223916 & -168.877 & transect* & -- & -- & -- \\
\hline 3 & 343.1601 & 1.358776 & 0.113509 & -168.532 & transect* & sympatry & -- & -- \\
\hline 3 & 343.4256 & 1.624319 & 0.099396 & -168.664 & transect* & red & -- & -- \\
\hline 3 & 343.4256 & 1.624319 & 0.099396 & -168.664 & transect* & white & -- & -- \\
\hline
\end{tabular}




\section{Figures:}

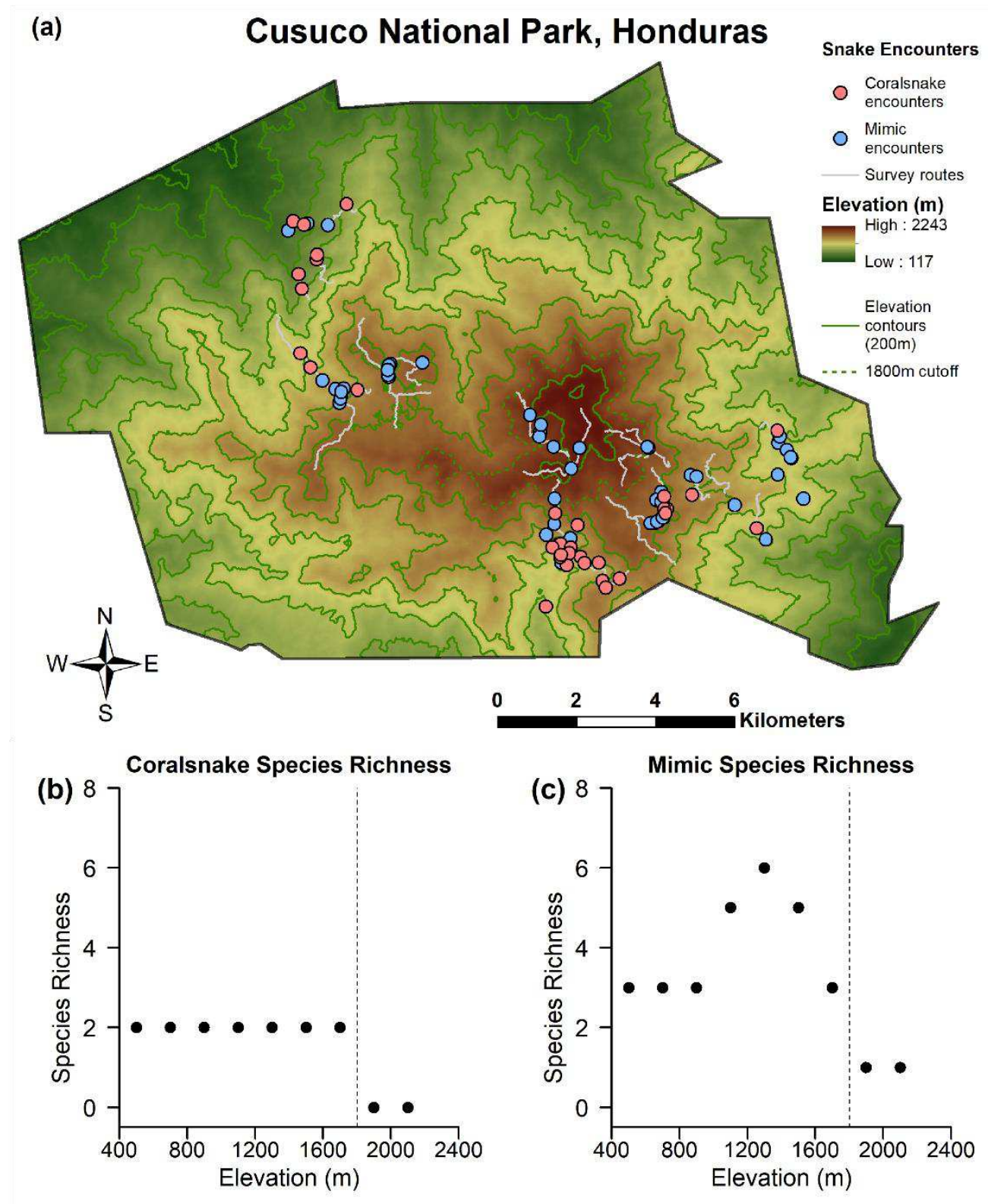

Figure 1. (a) Locations of coral snake and coral snake mimic encounters in Cusuco National Park, Honduras from 2007 to 2019. (b-c) Species richness of coral snakes and their mimics at differing elevations in Cusuco National Park, Honduras. The dotted line at $1800 \mathrm{~m}$ represents the range edge of coral snakes. Note that neither coral snake species in the park is found above $1800 \mathrm{~m}$, but mimics can be found up to the highest elevations. 

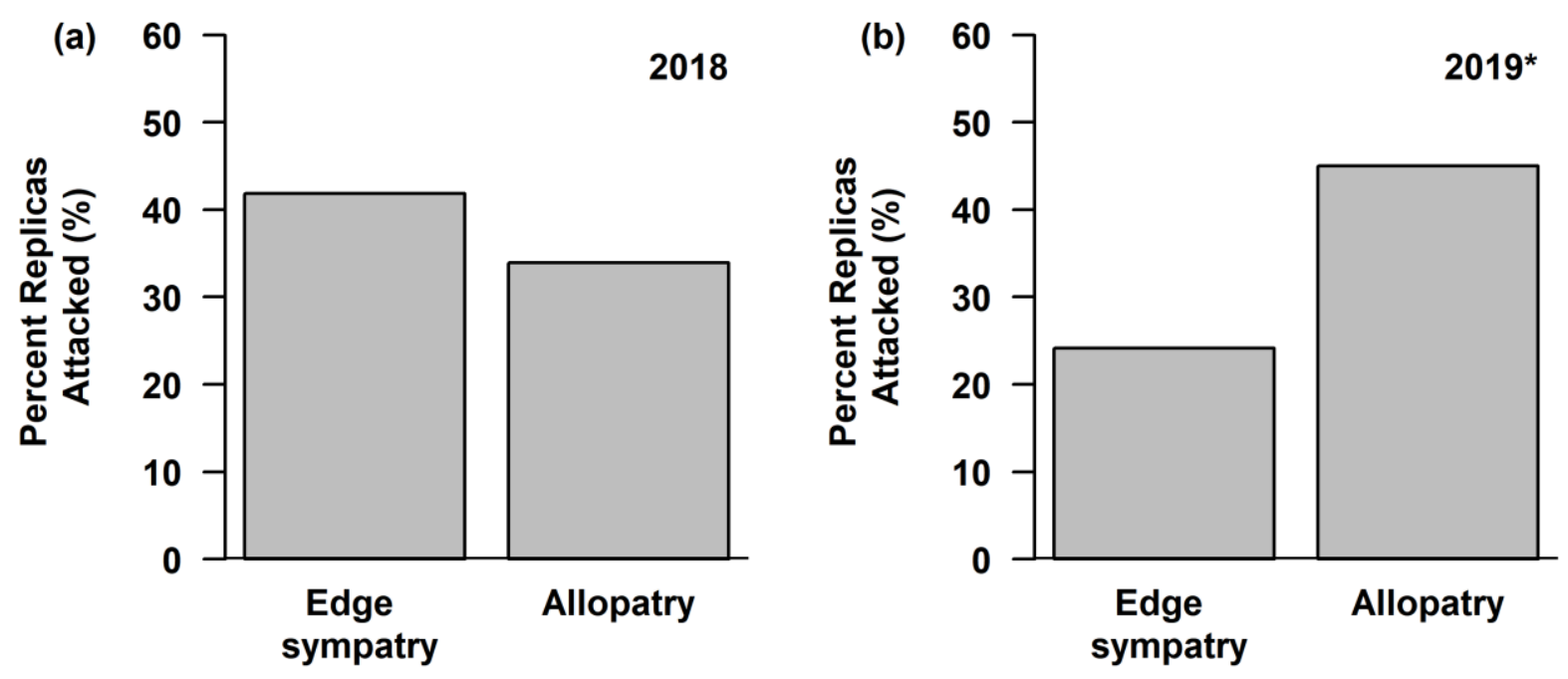

Figure 2. Attack rates on clay snake replicas in edge sympatric and allopatric habitats in 2018 (a) and 2019 (b). An asterisk (*) indicates significance from contingency analyses. Attack rates in 2019 were higher in allopatry than in edge sympatry, while attack rates in 2018 did not differ between edge sympatry and allopatry. 

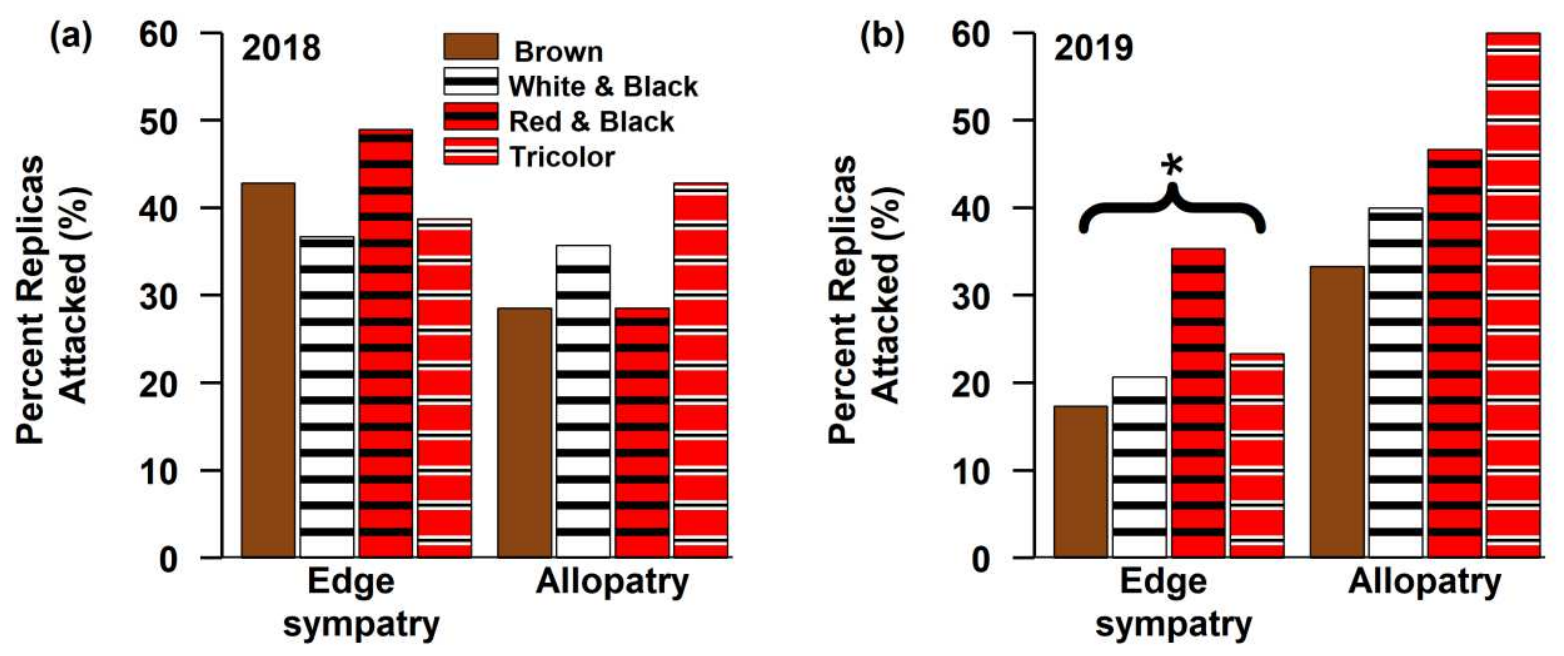

Figure 3. Attack rates on clay snake replicas with four different color patterns in areas of edge sympatry and allopatry in 2018 (a) and 2019 (b). An asterisk (*) indicates significance from contingency analyses. Replicas with mimetic patterns (white-and-black-banded, red-and-black banded, or tricolored) were attacked more than brown replicas in almost all scenarios. 

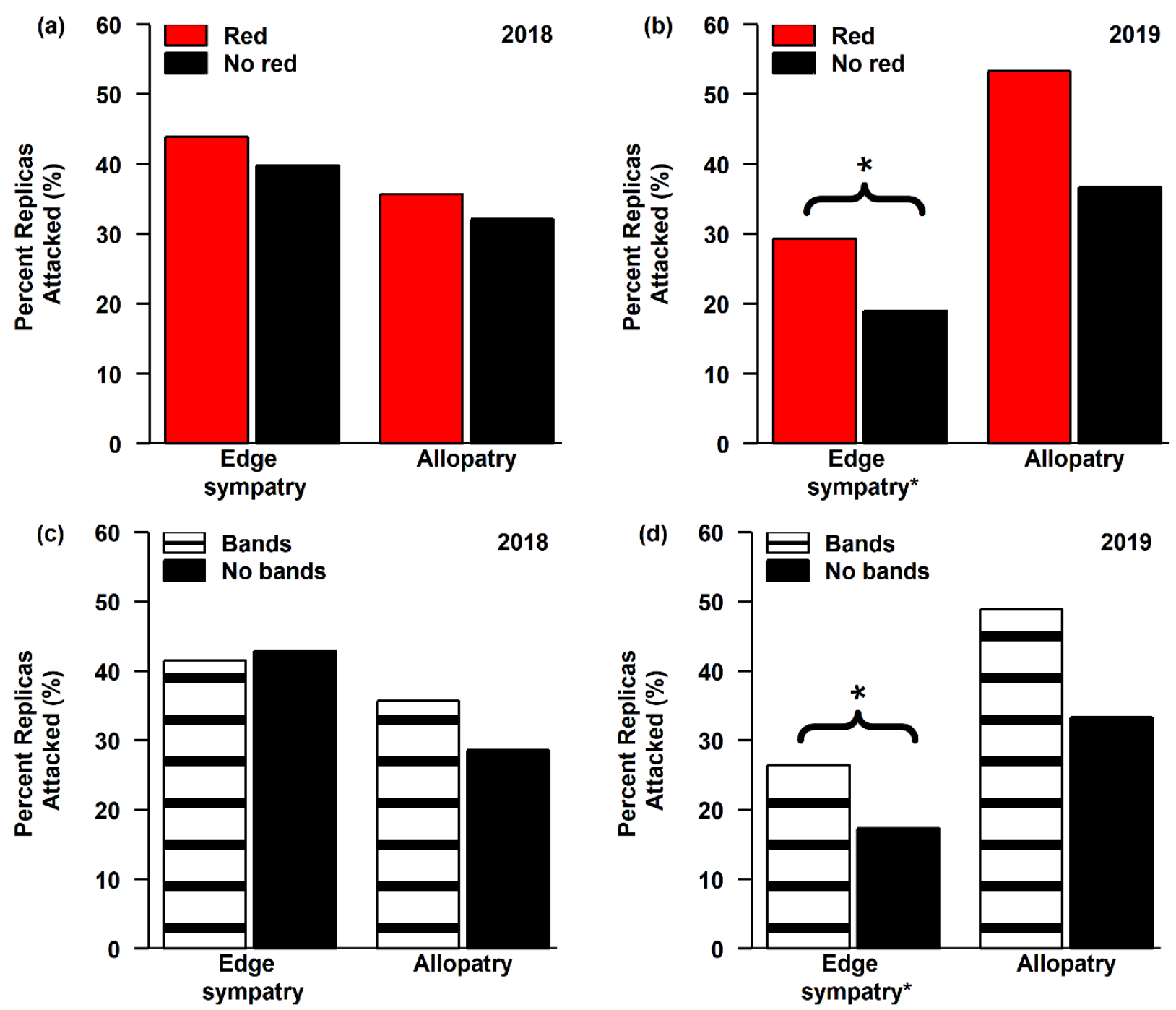

Figure 4. (a-b) Attack rates on clay snake replicas with and without the color red included in their patterns in areas of edge sympatry and allopatry. (c-d) Attack rates on clay snake replicas with and without banded color patterns in areas of edge sympatry and allopatry. An asterisk (*) indicates significance from contingency analyses. Replicas with red or bands were almost always attacked more than replicas without those traits. 


\section{Figures}

(a) Cusuco National Park, Honduras
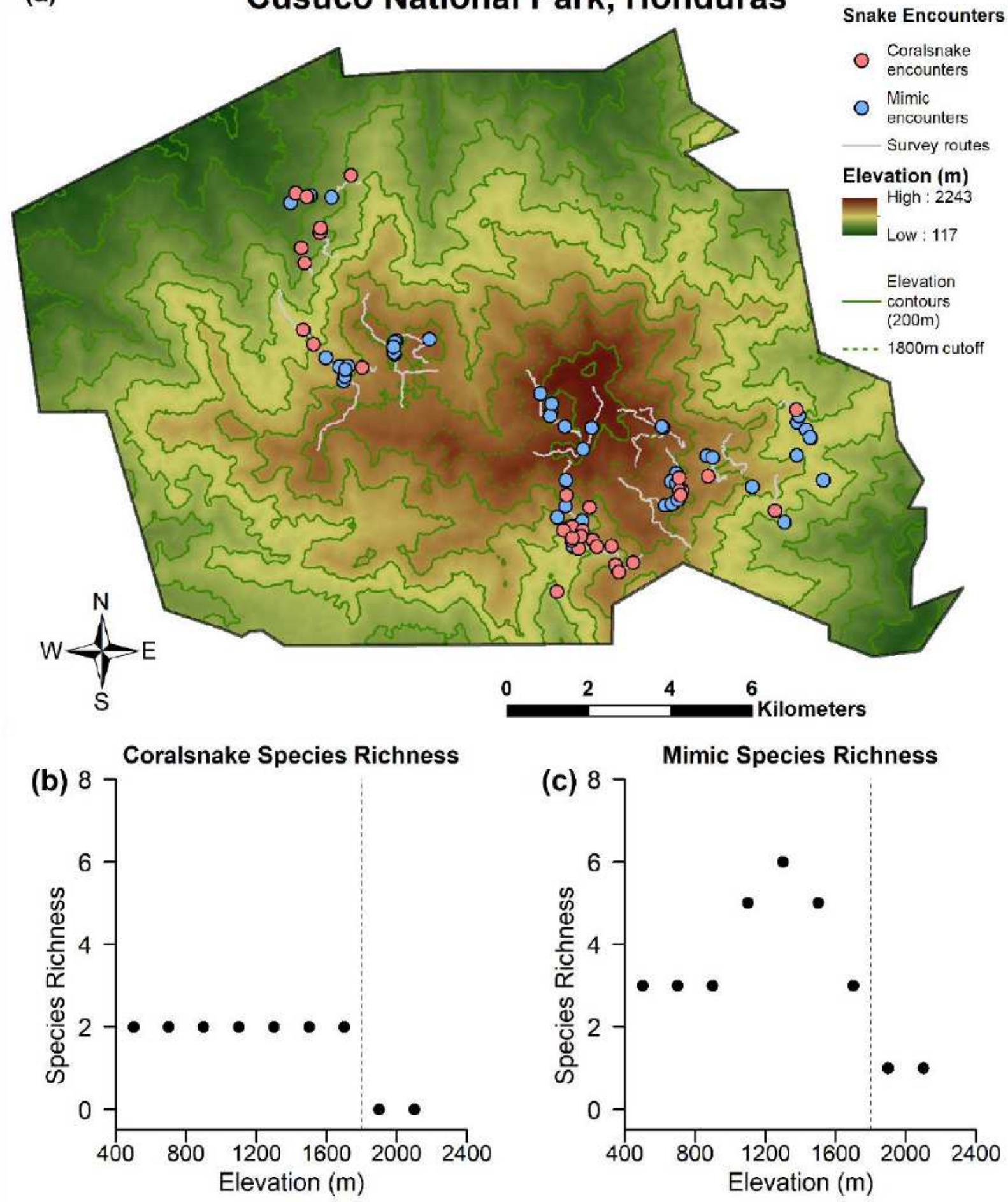

Figure 1

(a) Locations of coral snake and coral snake mimic encounters in Cusuco National Park, Honduras from 2007 to 2019. Note: The designations employed and the presentation of the material on this map do not imply the expression of any opinion whatsoever on the part of Research Square concerning the legal 
status of any country, territory, city or area or of its authorities, or concerning the delimitation of its frontiers or boundaries. This map has been provided by the authors. (b-c) Species richness of coral snakes and their mimics at differing elevations in Cusuco National Park, Honduras. The dotted line at $1800 \mathrm{~m}$ represents the range edge of coral snakes. Note that neither coral snake species in the park is found above $1800 \mathrm{~m}$, but mimics can be found up to the highest elevations.
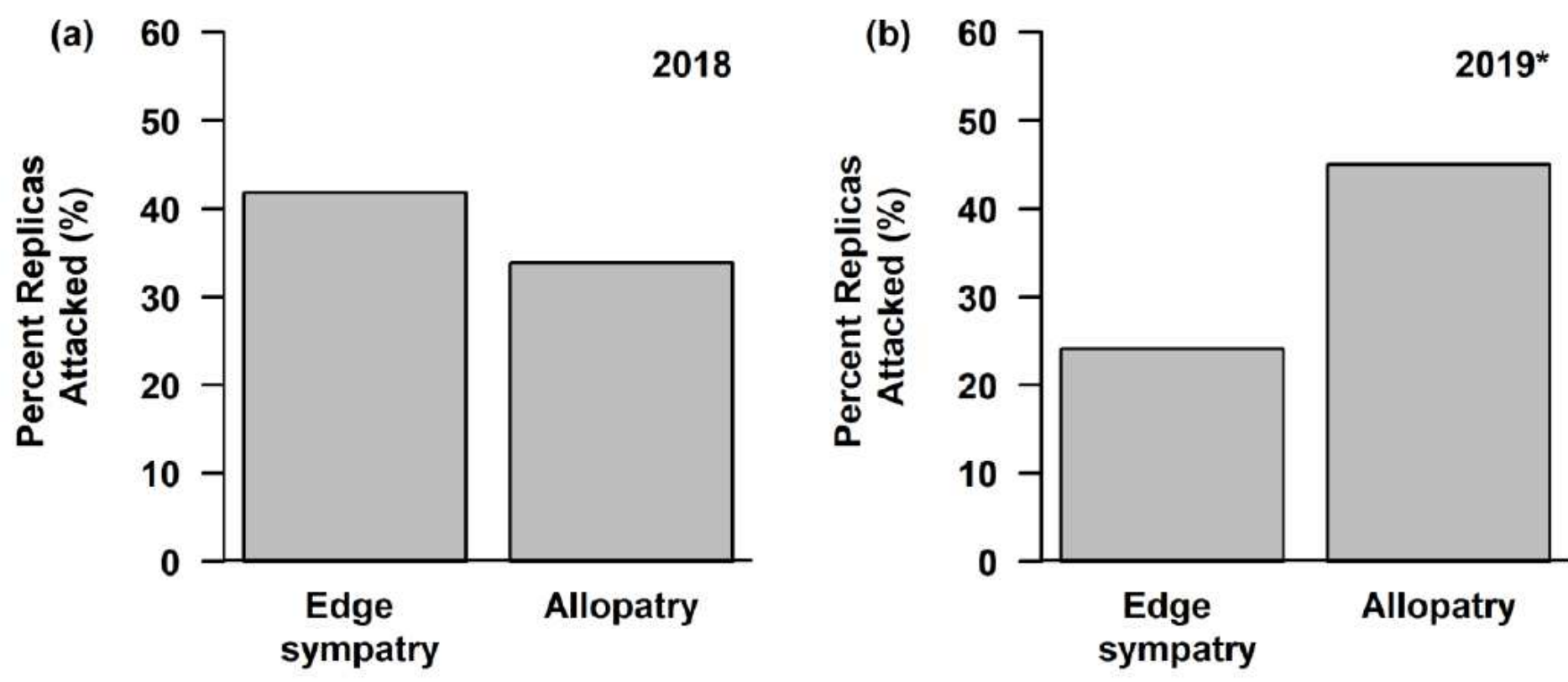

Figure 2

Attack rates on clay snake replicas in edge sympatric and allopatric habitats in 2018 (a) and 2019 (b). An asterisk (*) indicates significance from contingency analyses. Attack rates in 2019 were higher in allopatry than in edge sympatry, while attack rates in 2018 did not differ between edge sympatry and allopatry.
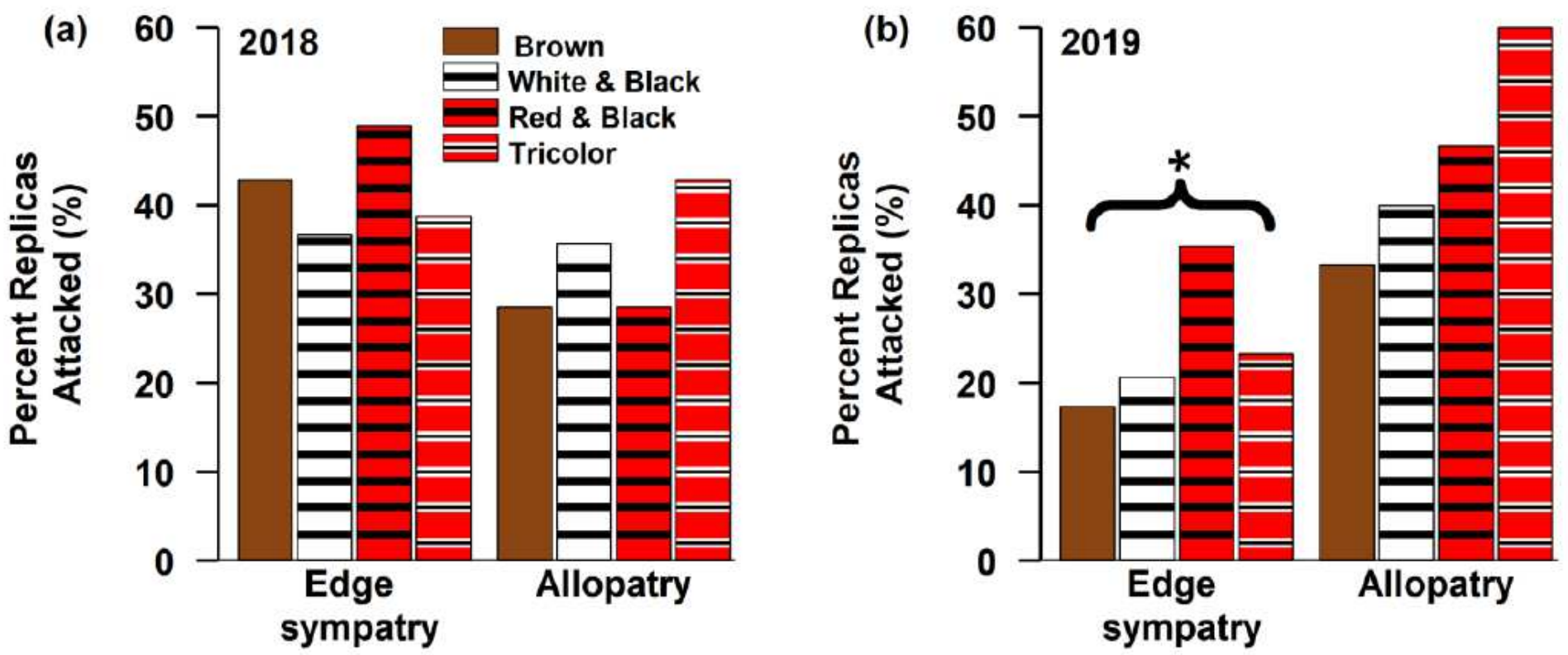


\section{Figure 3}

Attack rates on clay snake replicas with four different color patterns in areas of edge sympatry and allopatry in 2018 (a) and 2019 (b). An asterisk (*) indicates significance from contingency analyses. Replicas with mimetic patterns (white-and-black-banded, red-and-black banded, or tricolored) were attacked more than brown replicas in almost all scenarios.
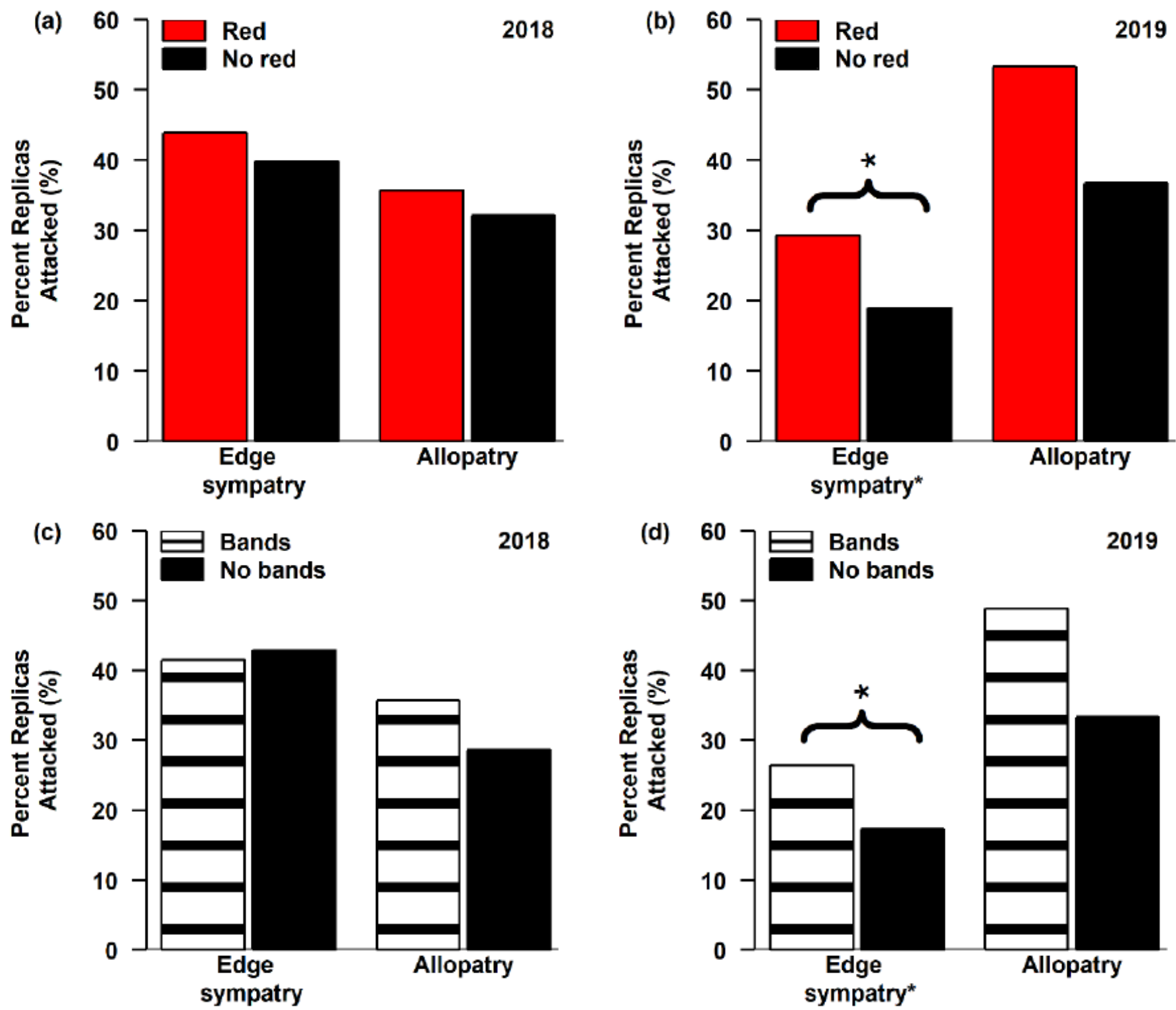

Figure 4

(a-b) Attack rates on clay snake replicas with and without the color red included in their patterns in areas of edge sympatry and allopatry. (c-d) Attack rates on clay snake replicas with and without banded color patterns in areas of edge sympatry and allopatry. An asterisk (*) indicates significance from contingency analyses. Replicas with red or bands were almost always attacked more than replicas without those traits. 


\section{Supplementary Files}

This is a list of supplementary files associated with this preprint. Click to download.

- Appendics.pdf

- SupplementryMaterial.pdf 